\title{
APRENDIZAGEM E CONHECIMENTO ESCOLAR: A INTERFACE PESQUISA E DOCÊNCIA
}

\author{
Jefferson Ildefonso da Silva*
}

\begin{abstract}
RESUMO
O presente texto tem como objetivo investigar as relações da prática da pesquisa com a prática docente, no âmbito da universidade. Busca constatar e analisar, na organização institucional, o desempenho de pesquisas acadêmicas orientadas para o processo de construção do conhecimento nos cursos de graduação. Pretende, assim, descobrir e compreender como se dá a interface da pesquisa como investigação da realidade com a prática docente como processo de ensino-aprendizagem no espaço da sala de aula. Especificamente, se propõe contribuir para o desenvolvimento de novas formas desse processo. São estudadas as raízes antropológicas e epistemológicas do conhecimento escolar como elementos fundadores da aprendizagem e do ensino e, conseqüentemente, dos comportamentos didáticos a respeito. $\mathrm{O}$ ensino necessita da prática institucional da pesquisa, não apenas para o fortalecimento dos conteúdos culturais e científicos a serem estudados, mas, sobretudo, para definir e desenvolver adequadamente o processo da construção do conhecimento escolar.
\end{abstract}

PALAVRAS-CHAVE: Aprendizagem. Conhecimento. Pesquisa.

Doutor em História e Filosofia da Educação (PUC-SP) e professor visitante do Programa de Pós-Graduação em Educação da Faculdade de Educação da Universidade Federal de Uberlândia. E-mail: jeffmar@terra.com.br 


\begin{abstract}
This study has the objective of investigating the relationship between the practice of research and the practice of teaching in the university environment. It seeks to establish and analyze the performance of academic research directed toward the process of constructing knowledge in undergraduate courses. As such, it aims to discover and understand how the interface between research as knowledge production and the practice of teaching is made within the classroom. Specifically, the purpose is to contribute to the development of new forms of the teachinglearning process. The anthropological and epistemological roots of school knowledge are studied as founding elements of learning and teaching and, consequently, of related didactic behavior. Teaching requires the institutional practice of research, not only for strengthening its cultural and scientific content, but also to define the way it constructs school knowledge.
\end{abstract}

KEYWORDS: Learning. Knowledge. Research.

\title{
Apresentação
}

O presente texto resulta de análises e reflexões sobre alguns conceitos polarizadores de um estudo em desenvolvimento, com o objetivo de investigar as relações da prática da pesquisa com a prática docente, no âmbito da universidade. Busca analisar, no contexto da organização institucional, a elaboração de fundamentos conceituais que possam explicitar os caminhos do processo de construção do conhecimento escolar. Especificamente, pretende descobrir e compreender como se dá a interface da pesquisa, como investigação da realidade e produção do conhecimento, e a prática docente no espaço da sala de aula, como processo de ensino dos saberes já construídos e em contínua reconstrução. Espera-se, não apenas abrir espaços para análises e reflexões sobre o conhecimento escolar, mas também contribuir

Educ. e Filos., Uberlândia, v. 22, n. 43, p. 11-32, jan./jun. 2008. 
para o surgimento de novas formas de desempenho do processo ensino-aprendizagem.

A pesquisa, no espaço acadêmico, tem sido assumida para caracterizar atividades diferenciadas que apresentam variados enfoques semânticos.

- Os Institutos ou Núcleos de Pesquisa desenvolvem a pesquisa científica de forma sistemática em laboratórios, em campo ou em acervos documentais e bibliográficos, por pesquisadores isolados ou em grupo. Estão voltados para a descoberta de novos fenômenos da natureza e criação de novas formas de conhecimento e atuação na realidade.

- Há também, na universidade, pesquisas que são assumidas diretamente por docentes com o objetivo de garantir maior articulação entre a atividade de ensino e a pesquisa. Possuem a marca acadêmica como definidora de suas análises e ações. Em algumas áreas, sobretudo das ciências físicas e biológicas, têm lugar relevante pesquisas, articuladas com projetos de ação e intervenção cujos objetivos visam atender às necessidades do desenvolvimento das ciências ou da produção de determinados procedimentos tecnológicos. Em outras áreas, sobretudo nas ciências sociais e da educação, os programas de pós-graduação desenvolvem suas pesquisas pela investigação e análise interpretativa dos fatos da sociedade, da cultura e da educação escolar.

- Atualmente, está sendo dado enfoque especial à pesquisa assumida como instrumento didático no processo de ensino, com o intuito de garantir nova qualidade para a aprendizagem. Nesse sentido, a prática da pesquisa é vista como capaz de conduzir o aluno a assumir seu lugar de agente de reconstrução do conhecimento. A literatura pedagógica apresenta inúmeros trabalhos sobre essa prática da pesquisa. Alguns trabalhos desenvolvem análises teóricas em busca de sua fundamentação como "princípio científico e educativo": Demo (1990). Outros buscam definir a pesquisa como metodologia e forma de ensino e "exercício de aprender a aprender": Moraes e Lima (2002), Moraes (2004), Demo (1997), Hernández e Ventura (1998), 
Fazenda (1992). Outros procuram caminhos diferentes orientados pelas características epistemológicas do conhecimento, para encontrarem aí os pontos de sustentação de relações novas entre pesquisa e aprendizagem na construção do conhecimento: Rodrigo e Arany (1998), Lopes (1999).

A constatação dessas diversas formas de pesquisa no interior das Instituições de Ensino Superior (IES) desperta atenção e provoca estudos para descobrir como se pode garantir o significado fundamental da pesquisa, ao mesmo tempo em que se abre para a ampliação de seu espaço e para a diversificação de sua prática.

A presente análise busca o significado da pesquisa em suas relações epistemológicas de produção do conhecimento pela relação sujeito-objeto, cognoscente e conhecido, ou melhor, a mutualidade dos sujeitos cognoscentes e incorporação do objeto conhecido. Essa relação constitui o elemento fundador e comum de qualquer processo de conhecimento como pesquisa ou como ensino-aprendizagem. Esse referencial epistemológico é assumido como elemento mediador e centro articulador das diversas formas de construção do conhecimento. Sobre essa afirmação, assim se exprime Severino (2002, p. 8):

O elemento básico do processo epistêmico, em sua condição originária, refere-se ao relacionamento entre sujeito e objeto, que se estabelece na atividade do conhecimento. O termo epistemologia refere-se prioritariamente a esse processo básico. [...] Desse modo, qualquer forma de conhecimento pressupõe uma referência epistemológica, ou seja, uma determinada visão de como a subjetividade humana se "apropria" de determinados conteúdos, tidos como conhecimentos.

\section{Caminhos da aprendizagem}

A aprendizagem, como atividade especificamente humana marcada pela intencionalidade definidora de objetivos, tem sua significação determinada pela própria compreensão do homem e de seu papel em sua construção existencial no mundo. O homem, 
como ser que não está pronto pela "natureza", precisa se construir como sujeito histórico e social, residindo aí a necessidade e a característica da aprendizagem humana como educação.

Um dos principais papéis reservado à educação consiste, antes de mais nada, em dotar a humanidade da capacidade de dominar o seu próprio desenvolvimento. Ela deve, de fato, fazer com que cada um tome o seu destino nas mãos e contribua para o progresso da sociedade em que vive, baseando o desenvolvimento na participação responsável dos indivíduos e das comunidades (DELORS, 1998, p. 82).

A compreensão do "fenômeno humano" como um processo de construção dos homens leva a considerar que tal processo se desenrola pela atuação dos próprios homens enquanto se relacionam mutuamente pela apropriação sucessiva das conquistas dos antepassados e pela integração coletiva socialmente partilhada. A apropriação e a partilha se fazem pela dependência e ligação com indivíduos em diferentes situações de inserção e participação históricas, das quais o conjunto dos homens recebe os feitos e as ações para ter condições de levar avante a jornada humana individual e coletiva.

Daí deriva a compreensão da educação e da aprendizagem em sua significação básica e comum. Saviani (1984, p. 51) assim vê o sentido da educação:

A educação, enquanto fenômeno, se apresenta como uma comunicação entre pessoas livres em graus diferentes de maturação humana, numa situação histórica determinada. Por isso se define como papel das instituições educacionais: "Ordenar e sistematizar as relações homem-meio para criar as condições ótimas de desenvolvimento das novas gerações, cuja ação e participação permita a continuidade e a sobrevivência da cultura e, em última instância, do próprio homem". Portanto, o sentido da educação, a sua finalidade, é o próprio homem, quer dizer sua promoção.

Portanto, as características do "fenômeno humano" estabelecem os parâmetros e a orientação da aprendizagem, assim 
como o conceito de aprendizagem determina a compreensão da educação, tanto em seu sentido amplo de formação do homem no contexto geral da sociedade, como em seu sentido escolar de construção de um tipo de conhecimento que, incorporando conflituosamente o conhecimento cotidiano e o conhecimento científico, busca oferecer condições aos alunos de atuar com segurança e criticamente em seu meio.

A proposta do caminho antropológico da construção histórica e social dos homens e o entendimento de que o conhecimento se origina no interior do agir transformador desses homens, podem levar a definir a aprendizagem como sustentação desse processo, no qual os homens históricos se ajudam mutuamente na construção significativa de sua própria existência.

No contexto da educação escolar, a aprendizagem tem papel primordial enquanto é a razão de ser e o objetivo da escola. É sua atividade-fim e meta buscada pela tarefa educativa. Por isso, ela determina as teorias pedagógicas e define suas metodologias. A história da educação revela o significado das propostas pedagógicas pelas análises de suas concepções sobre a aprendizagem.

A aprendizagem escolar não pode ter seu significado esvaziado pela sua assimilação simplista à aprendizagem ampla social ou a uma vaga formação do indivíduo ou da personalidade do ser humano. Sua especificidade passa pela mediação do conhecimento com todas as suas implicações de natureza epistemológica e de sua imbricação na tessitura cotidiana.

A cultura científica escolar de que falo é necessária como conhecimento específico diferenciado, tanto do conhecimento cotidiano como do propriamente científico. Trata-se de estabelecer um espaço intermediário no qual os processos de ensino traduzam e tornem compatíveis as concepções cotidianas implícitas com aspectos conceituais tácitos de maior complexidade, parte do quais poderiam ser adaptações ajustadas e simplificadas da estrutura histórica e conceitual da ciência, porém sem oferecer o conhecimento científico como único modelo e meta do conhecimento escolar (RODRIGO e ARNAY, 1998, p. 48).

Educ. e Filos., Uberlândia, v. 22, n. 43, p. 11-32, jan./jun. 2008. 
A aprendizagem recebe as determinações epistemológicas próprias da construção do conhecimento escolar e adquire formas definidas pelo contato e pela influência das relações escolares e da organização estrutural do espaço escolar. As metodologias sustentam e orientam os caminhos da aprendizagem. As relações dos diversificados agentes da educação escolar estabelecem contornos e configurações de maior complexidade e de conflitos, próprios da construção do conhecimento escolar que carrega, de sua parte, as divergências e as dificuldades inerentes ao encontro do conhecimento cotidiano com o conhecimento científico.

\section{Construção do conhecimento}

O conhecimento não está pronto e acabado, nem na natureza, nem na sociedade, nem no acervo cultural da humanidade. Só acontece quando o sujeito o elabora com os dados da natureza, com a atuação e as relações dos homens em sociedade e com a apropriação dos resultados da elaboração cognitiva e produtiva dos homens em seu processo histórico. Os saberes, como resultados e produtos elaborados do conhecimento, não carregam em si mesmos o significado próprio de conhecimento como atividade epistemológica, como "sageza":

Os antigos não puderam transmitir melhor a sua sageza; ela morreu com eles. Eis a razão pela qual aquilo que ledes é com certeza a borra e o resíduo dos antigos. [...] a sageza não se herda, conquistase; ela não é apanágio daqueles que podem estudar a sageza de outrem (SERRÃO, 1970, p. 22).

A tendência pragmática atual, que considera apenas o resultado em detrimento do processo, impede os homens de ultrapassarem os contornos já estabelecidos, limitando-se a rearranjos que não vão além de uma nova manipulação, de um novo formato de caráter reorganizacional. Tal tendência contamina o âmbito do conhecimento e o espaço da pesquisa ao limitar seu avanço para uma nova compreensão ideativa dos dados e elementos investigados e descobertos.

Educ. e Filos., Uberlândia, v. 22, n. 43, p. 11-32, jan./jun. 2008. 
A pesquisa científico-acadêmica, de ordem epistemológica, passa pelos diferentes dados da natureza, da sociedade e do conhecimento chamado "elaborado", para alcançar a produção de outro conhecimento como processo epistemológico que se faz na relação do sujeito com o objeto e como resultado comunicado e partilhado culturalmente. Assim, uma aprendizagem significativa se propõe ultrapassar a busca de dados existentes e definidos pelo já acontecido e alcançar a compreensão da realidade como "mundo complexo", como afirma Pierre Levy (2004) ao apontar que "a aprendizagem faz crescer a complexidade cognitiva em todas as direções do espaço e do sentido" (p. 23).

O conhecimento novo não está dado, não se descobre (como se já existisse), mas é construído e reconstruído pelo pesquisador como "elaborador epistemológico".

Ora, para que ocorra uma idéia, para que se conheça, é necessário que se verifique a existência de um sujeito capaz de idear e de um objeto suscetível de ser ideado. Por outras palavras dito: urge que a representação mental represente algo, esse desconhecido $x$ com que se defronta a nossa capacidade de conhecer (SERRÃO, 1970, p.16).

Esse significado epistemológico do processo de conhecimento envolve a atividade do sujeito e apresenta características semelhantes às do significado do trabalho humano analisado por Marx (1983, p. 149-151). Esse paralelo entre trabalho e conhecimento se mostra rico para definir os passos e as características epistemológicas do conhecimento. Segundo Marx, o processo de trabalho envolve:

- A ideação é considerada como objetivo e intencionalidade:

No fim do processo de trabalho obtém-se um resultado que já no início deste existiu na imaginação do trabalhador, e portanto idealmente. Ele não apenas efetua uma transformação da forma material; realiza, ao mesmo tempo, na matéria natural seu objetivo que sabe que determina, como lei, a espécie e o modo de sua atividade e ao qual tem de subordinar sua vontade (MARX, 1983, p. 149-150).

Educ. e Filos., Uberlândia, v. 22, n. 43, p. 11-32, jan./jun. 2008. 
No nível do conhecimento, é fundamental recuperar o papel do objetivo e da intencionalidade que levam ao rompimento da tendência empírica e pragmática que busca o conhecimento no objeto imediato já dado para a apropriação terminal do conhecimento.

Pela ideação, se pode reproduzir "espiritual e racionalmente a realidade", afirmando a convicção de que essa realidade se estende para além da imagem física do mundo:

O fisicalismo positivista é responsável pelo equívoco de ter considerado uma certa imagem da realidade como a realidade mesma, e um determinado modo de apropriação da realidade como o único autêntico (KOSIK, 1976, p. 25).

O sujeito cognoscente é antes de tudo consciência aperceptiva, onde a intencionalidade se expressa em teoria, como compreensão explicitamente reproduzida da realidade: "A teoria do conhecimento como reprodução espiritual da realidade põe em evidência o caráter ativo do conhecimento em todos os seus níveis" (KOSIK, 1976, p. 27).

- O objeto é formado por elementos prontos e encontrados na natureza, sem a intervenção do homem, ou então transformados em matéria-prima pelo trabalho anterior:

Todas as coisas, que o trabalho só desprende de sua conexão direta com o conjunto da terra, são objetos de trabalho preexistentes por natureza. [...] o objeto de trabalho apenas é matéria-prima depois de já ter experimentado uma modificação mediada por trabalho (MARX, 1983, p. 150).

O objeto do conhecimento não é inteligível em si mesmo, devendo passar pela atividade da práxis que o transforma e o faz significativo, podendo assim ser assumido pelo processo de ideação e reprodução espiritual ao deixar de ser "coisa em si" para se tornar "coisa para si": "O homem só conhece a realidade na medida em que ele cria a realidade humana e se comporta antes de tudo como ser prático" (KOSIK, 1976, p. 22). 
Assim compreendido, o conhecimento explicita o significado social e histórico que preside a criação da realidade pelo conjunto de todos os homens. O comportamento epistemológico supõe a compreensão do homem como sujeito que se constrói e constrói o mundo humano com os dados da natureza, da sociedade e da cultura, envolvendo conhecimento e transformação desses dados.

Aí se realiza o conceito de história não como acúmulo de feitos, mas como processo de reconstrução com os dados já elaborados, "na verdade, no sentido de que é um produto histórico, o resultado da atividade de toda uma série de gerações, cada uma das quais alçando-se aos ombros da precedente [...]" (MARX e ENGELS, 1979 , p. 67).

- O meio de trabalho é um conjunto de instrumentos e ferramentas que o trabalhador coloca entre si mesmo e o objeto de trabalho para conduzir a atividade em conformidade com o objetivo:

O objeto do qual o trabalhador se apodera diretamente [...] não é objeto de trabalho, mas o meio de trabalho. [...] Tão logo o processo de trabalho esteja em alguma medida desenvolvido de todo, necessita ele de meios de trabalho já trabalhados. [...] Além das coisas que mediam a atuação do trabalho sobre seu objeto e, por isso, servem, de um modo ou de outro, de condutor da atividade, o processo de trabalho conta, em sentido lato, entre seus meios com todas as condições objetivas que são exigidas para que o processo se realize (MARX, 1983, p. 150-151).

O conhecimento, que é sempre uma forma de se apropriar da realidade, postula mediações e instrumentos de apropriação que compreendem não só o conjunto das produções materiais e culturais dos homens em sociedade, mas também os métodos e as formas didáticas de condução nos caminhos da explicitação da realidade a ser apropriada:

O processo cognitivo se transforma em explicação dos fenômenos. A realidade é interpretada não mediante a redução a algo diverso de si mesma, mas explicando-a com base na própria realidade,

Educ. e Filos., Uberlândia, v. 22, n. 43, p. 11-32, jan./jun. 2008. 
mediante o desenvolvimento e a ilustração das suas fases, dos momentos do seu movimento (KOSIK, 1976, p. 29).

O processo de explicitação da realidade não é produto de intuições, nem se efetiva pela relação imediata, mas exige a presença e participação de homens envolvidos no processo de construção dessa realidade. Ele é ativado pela integração em um processo em curso pela ação dos demais homens e pela partilha que socialmente se faz. Daí nasce a necessidade da mediação dos outros homens e do uso de instrumentos e métodos para a explicitação e apropriação epistemológica da realidade:

Cada grau do conhecimento humano sensível ou racional, cada modo de apropriação da realidade, é uma atividade baseada na práxis objetiva da humanidade e, portanto, ligada a todos os outros vários modos, em medida maior ou menor. O homem sempre vê mais do que aquilo que percebe imediatamente (KOSIK, 1976, p. 24).

\section{- O produto se efetiva como}

uma transformação do objeto de trabalho, pretendida desde o princípio. O processo extingue-se no produto. Seu produto é um valor de uso; uma matéria natural adaptada às necessidades humanas mediante transformação da forma. $\mathrm{O}$ trabalho se uniu com seu objetivo. O trabalho está objetivado e o objeto trabalhado (MARX, 1983, p. 151).

No processo de produção do conhecimento, o produto só se perfaz na apropriação do saber pelo próprio sujeito. O processo se corrompe quando o aluno se torna detentor somente das sobras do conhecimento, de um saber que não surgiu de seu processo e que assim não tem condições de se tornar dele. Nesse sentido Ortega y Gasset (1966) diz que o estudar se torna alienação que faz do aluno um ser falso. Ele está diante da ciência pronta, em situação totalmente diferente daqueles que a criaram. Está cortado para ele o caminho da criatividade e da reconstrução necessária ao autêntico saber: 
En cambio, el estudiante se encuentra, desde luego, con la ciencia ya hecha, como con una serranía que se levanta ante él y le cierra su comino vital. [...] Porque la actividad misma, el hacer que la pedagogía regula y que llamamos estudiar, es en si mismo algo humanamente falso. [...] La solución a tan crudo y bicorne problema se desprende de todo lo que he dicho: no consiste en decretar que no se estudie sino en reformar profundamente ese hacer humano que es el estudiar y, consecuentemente, el ser del estudiante (p. 26-28).

A pesquisa, ao possibilitar a reconstrução da ciência, abre espaço para que o estudante se faça sujeito criador e apropriador do produto do estudar e recupere sua identidade.

No âmbito do conhecimento escolar, a integração com a prática e o fazer humano deve ser pressuposta e assumida para que ele não se desgarre no mundo do alheamento. A aprendizagem escolar deve, assim, se esforçar para manter firmes os liames dessa relação e não se perder em busca abstrata e teórica da recuperação da unidade perdida entre a teoria e a prática. A tendência excludente que opõe a postura espontânea do cotidiano à abordagem formal e metódica da ciência dificulta ao conhecimento estabelecer a integração dialética que os aproxima e os inclui pelo próprio tratamento escolar.

Em resumo, cada disciplina que forma o currículo escolar tem suas próprias restrições para se ligar à realidade cotidiana. A partir de determinados limites, relacionar conhecimento cotidiano e conhecimento científico é uma tarefa quase impossível. Tudo isso nos leva a aceitar, em último termo, que as disciplinas acadêmicas se justificariam para promover dentro do sistema educativo. Mas nem sempre servem para serem utilizadas como suportes que qualifiquem para uma compreensão mais científica da nossa realidade cotidiana (RODRIGO e ARNAY, 1998, p. 43-4).

\section{Ensino e conhecimento escolar}

As atividades acadêmicas têm no ensino seu espaço privilegiado, historicamente consolidado nas universidades brasileiras. O ensino está sujeito às variações das tendências 
pedagógicas e didáticas que se sucedem a partir das teorias da educação e da organização escolar. Entretanto, somente poderá garantir seu pleno significado enquanto se mantiver intrinsecamente unido à aprendizagem. Assim, o núcleo significante da educação escolar permanece sempre marcado pela relação ensino-aprendizagem, de tal forma que as considerações referentes à pesquisa e à extensão se fundamentam pelas suas relações de analogia com o ensino (ESTRELA, 1992).

A especificidade da aprendizagem escolar passa pela mediação do conhecimento com todas as implicações de sua natureza epistemológica que incorpora conflituosamente o conhecimento cotidiano e o conhecimento científico. Esse conhecimento escolar tem um significado próprio, exigindo uma revisão da leitura que o identifica imediatamente com o conhecimento científico e postulando, ao mesmo tempo, ir além do conhecimento cotidiano (RODRIGO e ARNAY, 1998; LOPES, 1997 e 1999).

Ao encaminhar a ambivalência do conhecimento escolar, Garcia (1988) faz a seguinte proposta:

No conhecimento escolar, propomos ir além da distinção entre problemas científicos e problemas cotidianos, mediante a proposta de problemas que sejam cotidianos, na medida em que afetam nossa vida, mas que, pela sua complexidade, requeiram a participação de outras formas de conhecimento em seu tratamento (p.98).

A construção desse conhecimento escolar está marcada por determinações epistemológicas que lhe são próprias e adquire formas específicas pelas metodologias que sustentam e orientam seus caminhos. As relações dos diversos e diferenciados agentes da educação escolar estabelecem contornos e configurações que revelam a grande complexidade da construção do conhecimento escolar e dos conflitos inerentes à busca de uma compreensão da cultura científica escolar compatível com o processo científico. Arnay (RODRIGO e ARNAY apud Arnay, 1998, p. 48) assim se posiciona:

A cultura científica escolar de que falo é necessária como conhecimento específico diferenciado, tanto do conhecimento cotidiano como 
do propriamente científico. Trata-se de estabelecer um espaço intermediário no qual os processos de ensino traduzam e tornem compatíveis as concepções cotidianas implícitas com aspectos conceituais tácitos de maior complexidade, parte dos quais poderiam ser adaptações ajustadas e simplificadas da estrutura histórica e conceitual da ciência, porém sem oferecer o conhecimento científico como único modelo e meta do conhecimento escolar.

As considerações sobre a importância da aprendizagem e a singularidade de seu papel na atividade escolar exigem que ela seja tratada no conjunto de seus agentes e de suas implicações e que seja mantida sua característica relacional com a atividade de ensino. Não se pode compreender uma auto-aprendizagem, nem uma aprendizagem originada genética e mecanicamente pelas forças naturais, presentes no interior do indivíduo. Sua significação histórica e social requer a interferência e a influência do outro, como sujeito do ensino e portador das conquistas históricas da humanidade, capazes de estabelecer a plataforma de sustentação para a caminhada dos que vão se incorporando ao conjunto dos que estão, no presente, se construindo.

A produção da vida, tanto da própria, no trabalho, como da alheia, na procriação, aparece agora como dupla relação: de um lado, como relação natural, de outro como relação social - social no sentido de que se entende por isso a cooperação de vários indivíduos, quaisquer que sejam as condições, o modo e a finalidade. [...] isto, na verdade, no sentido de que é um produto histórico, o resultado da atividade de toda uma série de gerações, cada uma das quais alçando-se aos ombros da precedente, desenvolvendo sua indústria e seu comércio, modificando a ordem social de acordo com as necessidades alteradas (MARX e ENGELS, 1979, p. 42 e 67).

As questões clássicas da especificação do papel do professor e do aluno percorreram caminhos que, ao valorizar a atuação do aluno, manifestaram contraditoriamente um novo papel para o docente. $\mathrm{O}$ ensino deixou de ser considerado como um processo simplista de transmissão de conhecimento, e vem se consolidando pela vinculação com a produção do próprio conhecimento.

Educ. e Filos., Uberlândia, v. 22, n. 43, p. 11-32, jan./jun. 2008. 


\section{Pesquisa docente e construção do conhecimento}

A recuperação do significado originário do conhecimento, como reconstrução e descoberta do novo, amplia a compreensão das relações do ensino com a produção do conhecimento e postula a presença da pesquisa na atividade docente.

A atitude receptiva e a simples reprodução não apenas são insuficientes para a reelaboração do conhecimento, como não têm condições de responder às demandas do processo acelerado das mudanças da realidade no mundo atual. Igualmente, os métodos ativos de ensino, tais como a prática pedagógica os tem desenvolvido, se mostram também insuficientes para formar o aluno como sujeito pleno da produção do conhecimento.

$\mathrm{Na}$ atividade de pesquisa, o ato investigador possui características bem diferentes:

[Este ato se caracteriza] como choque de um sujeito indagador, movido por finalidades subjetivas e dotado de instrumentos objetivos, contra uma realidade que lhe opõe resistência, cuja superação constitui para ele uma necessidade vital, uma natureza que o desafia e que a domine, e lhe cria curiosidade e interesses, a que não pode fugir (PINTO, 1969, p. 453).

Tal atitude do sujeito investigador se identifica com a do sujeito cognoscente. Pode-se mesmo concluir que não há conhecimento que não envolva, de uma forma ou outra, o ato de pesquisa. Se no passado a atividade da pesquisa se recolheu aos átrios de grupos seletos de pesquisadores, hoje ela tem seu espaço ampliado pela presença no cotidiano das salas de aula, na árdua tarefa docente do trato dos saberes elaborados, assumidos no processo de reconstrução do conhecimento entre professores e alunos.

A força pedagógica da pesquisa, como princípio científico e educativo (DEMO, 1990), alimenta o caráter inovador da tarefa do ensino e exige do aluno assumir seu papel de sujeito no cotidiano da sala de aula. As inovações metodológicas que não incorporarem a pesquisa como princípio didático, correm o risco de se limitarem a agitadoras superficiais das atividades escolares, sem alcançar o

Educ. e Filos., Uberlândia, v. 22, n. 43, p. 11-32, jan./jun. 2008 
âmago do conhecimento. Assim como os métodos tradicionais levaram o aluno à passividade receptiva ou reprodutiva, os modernos métodos ativos não estão atingindo o sujeito-aluno em seu agir fundamental e essencial. $\mathrm{O}$ aluno continua distanciado do exercício de aprender como sujeito do conhecimento reconstruído.

De sua parte, o professor se sente atraído pela pesquisa como seu instrumento primordial de conduzir o aluno à construção do conhecimento e à produção das condições necessárias ao desenvolvimento e reelaboração daqueles conhecimentos. $\mathrm{O}$ ensinar pela pesquisa lhe dá as condições de se postar como parceiro e como condutor competente da ação conjunta.

É claro que isto levanta desafios temerários ao professor, porque vai se desfazendo o auditório cativo, exige-se cada vez mais um parceiro sempre totalmente presente ao trabalho, a capacidade de liderança torna-se tanto mais necessária (DEMO, 1997, p. 17).

O professor repetidor ou mero apresentador de teorias alheias será substituído pelo professor-autor que reconstruiu um projeto pedagógico com proposta elaborada coerentemente, questionadora e intrigante para o aluno. Esse desafio se põe hoje para a educação e especificamente para a escola, levando-a a assumir a pesquisa como seu modo de educar. A competência do professor se reafirma como indispensável para a condução do processo de ensino pela pesquisa, exigindo dele iniciativa criadora e segurança de condução.

O projeto pedagógico próprio, assim, não tem por finalidade mostrar apenas que se leram autores, ou que se tem noção de algumas teorias, ou que se é capaz de colocar por escrito idéias dos outros. Ao contrário, objetiva mostrar a competência de reconstrução questionadora própria. Deve usar todos os autores pertinentes, não para esconder-se atrás deles, mas para fazer-se, tanto melhor se com fundamentação, autor também. Deve sobretudo garantir competência em pesquisa e em formulação (DEMO, 1997, p. 40-1).

As relações da pesquisa com a produção do conhecimento científico continuam passando por revisões conceituais, em busca

Educ. e Filos., Uberlândia, v. 22, n. 43, p. 11-32, jan./jun. 2008. 
de novas referências. Os questionamentos sobre a indução e os "paradigmas científicos" levam a estabelecer novos contornos para o espaço do pesquisador: pede-se que ele vá além do investigador objetivo de um produto elaborado, para se postar como produtor que é criador e aprendiz (ALVES-MAZZOTTI e GEWANDSZNAJDER, 1998).

Com isso, muitos educadores começaram a ver no processo da pesquisa um caminho para orientar a metodologia da aprendizagem ativa e criadora (HERNÁNDEZ e VENTURA, 1998). Ao professor é pedida competência didática e metodológica que o torne capaz de orientar e utilizar-se dos instrumentos para conduzir ordenadamente o processo de pesquisa dos alunos.

Entretanto, é mister superar o engodo metodológico de ver nos métodos e instrumentos a força geradora do conhecimento, com esquecimento das relações epistemológicas. A atitude científica e didática exigida ao professor requer que sua formação seja marcada pela experiência da pesquisa em seus anos de formação.

O professor necessita de adquirir domínio da ciência pedagógica a fim de intervir eficazmente no campo real. Isso não passa apenas pela aquisição de conhecimentos, mas fundamentalmente pela mudança de atitudes, por novos hábitos de rigor e de cientificidade, que lhe proporcionem um distanciamento na análise dos fenómenos que o envolvem e sobre os quais terá de actuar. Ora, só a iniciação na investigação lhe permitirá operar essa mudança de atitudes (ESTRELA, 1992, p. 59-60).

Essa formação levá-lo-á a organizar o currículo e suas atividades em aula por meio de formas inquiridoras e investigativas capazes de estabelecer a pesquisa como fazer cotidiano dos alunos, facilitando-lhes "a construção de seus conhecimentos, a transformação da informação procedente dos diversos saberes disciplinares em conhecimento próprio". (HERNÁNDEZ e VENTURA, 1998, p. 61). Entre as diversas formas de assumir a pesquisa na docência está a proposta dos projetos de trabalho, considerados como uma maneira de manter a prática da pesquisa sempre presente na tarefa do ensino. 
Assim, a pesquisa em sala de aula se põe como elemento renovador do ensino e gerador da qualidade do conhecimento buscada pela educação escolar. Junto com o conteúdo científico e cultural da aprendizagem, o aluno é levado ao aprendizado do saber aprender. Conseqüentemente, a educação escolar estará mais bem aparelhada para cumprir a missão de formar homens que possam construir a humanidade no torvelinho das mudanças e no afrontamento das rupturas de paradigmas do mundo globalizado.

Entretanto, esses avanços na busca do lugar da pesquisa no processo de ensino-aprendizagem, na medida em que se desenvolvem, geram a necessidade de explicitar e aprofundar as relações de caráter epistemológico do ensino com a pesquisa.

Em primeiro lugar, a natureza do conhecimento escolar atinge diretamente os caracteres específicos da pesquisa quando essa é usada como instrumento didático de ensino-aprendizagem, podendo reduzi-la a uma metodologia formal. Por isso, é fundamental pôr-se o problema de saber se a pesquisa científica como produtora de conhecimento pode ser compatibilizada apenas por meio do conhecimento escolar e continuar mantendo sua identidade.

Outra questão é atingir o próprio significado da produção epistemológica do conhecimento que vai muito além de uma simples relação metodológica. Por isso, não basta que o ensino se limite à aprendizagem do aprender a aprender, pois essa afirmação parece enfatizar e se restringir ao aprendizado do processo de aprender, sem estar diretamente fundamentada no processo efetivo de construir o conhecimento. O ponto de chegada, o resultado do processo, não está no encontro ou na manipulação do objeto de conhecimento como ele já se encontra, mas no produto ou resultado que nasce do processo, isto é, no novo conhecimento. Por isso, o sentido do aluno como sujeito não se limita a assumir o processo, mas exige que ele construa o resultado como seu novo conhecimento.

Essas considerações sustentam e definem o significado diferenciado da relação entre a pesquisa docente e a construção do conhecimento escolar. Assim, a pesquisa se vê ampliada ao se

Educ. e Filos., Uberlândia, v. 22, n. 43, p. 11-32, jan./jun. 2008. 
tornar um caminho de construção do conhecimento escolar, além de produtora de ciência (SILVA, 2000). Mais ainda, sua função de caracterizar a instituição e a ambiência universitárias se fortalece e se abre para formas diversificadas de atuação.

\section{Considerações finais}

As propostas e as práticas de pesquisa na Universidade definem, de forma marcante, o caráter universitário das suas atividades e da sua estruturação institucional. A institucionalização da pesquisa docente conduz à recuperação do ensino como espaço privilegiado, historicamente consolidado nas universidades brasileiras e à sua defesa contra as tentativas simplificadoras de transformá-lo em simples tarefa de transmissão do conhecimento produzido.

No acontecer cotidiano da universidade, a efetivação dessa nova perspectiva da pesquisa não deixa de ser um desafio, pois os caminhos concretos não se mostram ainda bem definidos e consolidados pela prática habitual. O fazer cotidiano e institucionalizado da universidade poderá ir construindo e definindo as formas de efetivar essas considerações da análise pedagógica.

A primeira iniciativa poderia ser a implementação institucional das atividades de pesquisa dos docentes. Preocupar-se com as pesquisas e gerenciá-las é uma das formas de as IES se situarem no contexto das políticas educacionais e de adquirirem os instrumentos necessários para participação de projetos e intercâmbios importantes para a convivência universitária.

O desenvolvimento de investigações poderá abrir caminhos para definir as formas de envolvimento das IES da região na tarefa conjunta de integrar, no contexto nacional, uma política regional de educação e alcançar a almejada qualidade científica e acadêmica exigida ao ensino e à pesquisa no momento atual. Entretanto, o cumprimento dessa tarefa torna-se muito mais difícil enquanto os estudos e as pesquisas não possuírem, dentro das IES, um espaço institucional adequado. 
O ensino necessita da prática institucional da pesquisa, não apenas para o fortalecimento dos conteúdos culturais e científicos ou para a sustentação e abastecimento das disciplinas a serem ensinadas. O mais importante é procurar e encontrar os caminhos de sua prática no desenvolvimento do ensino para a construção do conhecimento escolar.

\section{Referências}

ALVES-MAZZOTTI, Alda; GEWANDSZNAJDER, Fernando. O método nas ciências naturais e sociais: pesquisa quantitativa e qualitativa. São Paulo: Pioneira, 1998.

DEMO, Pedro. Pesquisa: princípio científico e educativo. São Paulo: Cortez / Autores Associados, 1990.

Educar pela pesquisa. São Paulo; Campinas: Autores Associados, 1997.

DELORS, Jacques (Org.). Educação: um tesouro a descobrir. Relatório para a UNESCO da Comissão Internacional sobre a Educação para o século XXI. São Paulo: Cortez; Brasília: MEC/ UNESCO, 1998.

ESTRELA, Albano. Pedagogia, ciência da educação? Porto: Porto Editora, 1992.

FAZENDA, Ivani (Org.). Novos enfoques da pesquisa educacional. São Paulo: Cortez, 1992.

GARCIA, Francisco Luiz. Introdução crítica ao conhecimento. Campinas: Papirus, 1988.

HERNÁNDEZ, Fernando; VENTURA, Montserrat. A organização do currículo por projetos: o conhecimento é um caleidoscópio. 5. ed. Porto Alegre: Artes Médicas, 1998. 
KOSIK, Karel. Dialética do concreto. 2. ed. Rio de Janeiro: Paz e Terra, 1976.

LEVY, Pierre. Aprender em um mundo complexo. Folha de São Paulo - Sinapse. São Paulo, p. 23, 29 jun. 2004.

LOPES, Alice Ribeiro Casimiro. Conhecimento escolar: ciência e cotidiano. Rio de Janeiro: EdUERJ, 1999.

LOPES, Alice Ribeiro Casimiro. Conhecimento escolar: interrelações com conhecimentos científicos e cotidianos. Contexto e Educação, v. 11, n. 45, p. 40-59, jan./mar. 1987.

MARX, Karl. O capital: crítica da economia política. São Paulo: Abril Cultural, 1983. v. 1/I.

MARX, Karl; ENGELS, Friederich. A ideologia alemã. 2. ed. São Paulo: Ciências Humanas, 1979.

MORAES, R.; LIMA, V.M.R. Pesquisa em sala de aula: tendências para a educação em novos tempos. Porto Alegre: EDIPUCRS, 2002.

MORAES, Roque. Educar pela Pesquisa: exercício de aprender a aprender. Porto Alegre: PUCRS, 2004. Apostila.

ORTEGA Y GASSET, José. Unas lecciones de Metafísica. Madrid: Alianza Editorial, 1966. Lección Primera, p. 9-30.

PINTO, Álvaro Vieira. Ciência e existência: problemas filosóficos da pesquisa científica. Rio de Janeiro: Paz e Terra, 1969.

RODRIGO, María José; ARNAY, José. (Org.). Conhecimento cotidiano, escolar e científico: representação e mudança. São Paulo: Ática, 1998. 
SAVIANI, Dermeval. Educação: do senso comum à consciência filosófica. 4. ed. São Paulo: Cortez; Autores Associados, 1984.

SERRÃO, Joel. Iniciação ao filosofar. Lisboa: Sá da Costa, 1970.

SEVERINO, Antonio Joaquim. A pesquisa qualitativa e suas referências epistemológicas. Cadernos de Ensaios e Pesquisas, Niterói, v. 3, n. 7, p. 7-18, jan./jun. 2002.

SILVA, Jefferson Ildefonso da. Pesquisa e conhecimento científico: ampliando o espaço da pesquisa na comunicação e apropriação do conhecimento. Ícone, Uberlândia, v. 6, n.1, p. 6-66, jan./jun. 2000. 